\title{
Aprofundando a compreensão da aprendizagem docente
}

\author{
Deeper understanding of learning from teaching
}

\author{
João Paulo Camargo de Lima ${ }^{1}$. Marinez Meneghello Passos ${ }^{2}$ • \\ Sergio de Mello Arruda ${ }^{3}$. Viviane Vanessa Döhl ${ }^{4}$
}

\begin{abstract}
Resumo: Este artigo apresenta a aplicação simultânea de dois instrumentos de análise, recentemente criados: a Matriz 3x3, entendida como um instrumento para a análise da ação docente em sala de aula; e os Focos da Aprendizagem Docente (FAD). Os instrumentos foram utilizados na análise de entrevistas realizadas com três estudantes da licenciatura em Física durante a execução do estágio supervisionado. A Matriz 3x3 foi aplicada aos dados categorizados pelos FAD como uma forma de aprofundar a compreensão dos indícios de aprendizagem docente evidenciados na análise das entrevistas. Por meio da utilização dos instrumentos, foi possível identificar, nos sujeitos estudados, as principais evidências nas relações construídas com conteúdo, o ensino e a aprendizagem; e suas interações com os Focos de Aprendizagem Docente. Por fim, o artigo demonstra possibilidades de articulação entre dois campos de estudo aparentemente sem contato, como a formação de professores e a educação informal.
\end{abstract}

Palavras-chave: Ensino de física. Matriz 3x3. Aprendizagem docente. Formação inicial de professores.

\begin{abstract}
This paper presents the simultaneous application of two recently created analytical tools: the Matrix 3x3, understood as a tool for the analysis of teaching activities in the classroom, and the Foci of Learning to Teaching (FAD). We used two analytical tools in the analysis of interviews with three students taking an undergraduate program for physics teachers (Licenciatura in Physics) during the execution of supervised training. It was applied the Matrix $3 \times 3$ to the data categorized by FAD as a way to deepen understanding the evidence of learning from teaching disclosed in the analysis of the interviews. By using the instruments, we identified the main evidence in the relationships built through the content, teaching and learning and its interactions with the Foci of Learning to Teaching. Finally, the paper demonstrates possibilities of articulation between two seemingly different fields without contact, such as teacher training and informal education.
\end{abstract}

Keywords: Physics teaching. Foci of learning to teaching. Initial training teachers.

\footnotetext{
${ }^{1}$ Departamento Acadêmico de Física, Universidade Tecnológica Federal do Paraná (UTFPR), campus Londrina, Avenida dos Pioneiros, 3.131, Morumbi, CEP 86036-370, Londrina, PR, Brasil. E-mail: <joaopaulo@utfpr.edu.br>.

${ }^{2}$ Departamento de Matemática, Universidade Estadual de Londrina (UEL), Londrina, PR, Brasil.

${ }^{3}$ Departamento de Física, Universidade Estadual de Londrina (UEL), Londrina, PR, Brasil.

${ }^{4}$ Universidade Tecnológica Federal do Paraná (UTFPR), Toledo, PR, Brasil.
} 


\section{Introdução}

A cada ano, novos professores são chamados a assumir seu lugar dentro das complexas e múltiplas dimensões que configuram a sala de aula. Neste sentido, o início de sua prática profissional, em especial o estágio supervisionado, possui o papel importante na aprendizagem para a docência e na construção da identidade profissional dos futuros professores. Ao inseri -los no contexto educativo, o estágio pode propiciar o estabelecimento de relações com todo o ambiente escolar: com o professor da escola, com os alunos, os colegas estagiários, diretores, pedagogos etc., possibilitando, dessa maneira, a aprendizagem com aqueles que possuem mais experiência, sendo considerado, por muitos, a fase mais importante do desenvolvimento profissional docente (HARGREAVES, 1994).

O estágio supervisionado, de fato, pode possibilitar experiências didático-pedagógicas que proporcionam experiências inovadoras e a mobilização dos saberes necessários para a atuação profissional em sala de aula. Esse momento pode ou deve ser aquele em que o estudante procura compreender o processo de ensino em seu todo, e construir, refletir, legitimar e consolidar sua identidade docente (PIMENTA; LIMA, 2004). Para os pesquisadores da área de formação de professores, poderíamos dizer que este momento específico

[...] trata-se, portanto, entre outras questões, de compreender de que forma os alunos futuros professores articulam entendimentos do que significa tornar-se e ser professor com as suas experiências de aprendizagem no contexto da formação e no contexto da prática de ensino, mas também com as suas biografias e modos de interação com os outros. (FLORES, 2012, p. 93)

Compreender este processo de tornar-se professor é essencial para progredirmos nas investigações acerca da prática docente, bem como entender a maneira pela qual os professores iniciantes se desenvolvem profissionalmente. Implica considerar as formas com que aprendem a ensinar e a analisar os complexos fatores pessoais e contextuais que influenciam seu crescimento profissional (FLORES, 2004).

Diante desse cenário, o uso de modelos e analogias pode nos auxiliar no entendimento desta complexa dimensão em que se configura a prática profissional. Nas mais variadas temáticas de pesquisa na área de educação e na formação de professores, a utilização de analogias, modelos e metáforas tem sido importante para um avanço nos estudos e no desenvolvimento teórico, como, por exemplo, a ideia de lentes analíticas (GEE, 2000; LUEHMANN, 2007) e a utilização de metáforas (ARRUDA; BACCON, 2007; THOMAS; BEAUCHAMP, 2011).

Como sugerem Petrie e Oshlag (1993), as analogias, as metáforas e os modelos, podem providenciar uma ligação racional entre aquilo que se conhece e o radicalmente desconhecido. Neste sentido, gostaríamos de apresentar dois trabalhos desenvolvidos recentemente, que podem significar um avanço e nos auxiliar em estudos da aprendizagem docente. Seriam eles: o instrumento para análise da ação do professor em sala de aula (ARRUDA; LIMA; PASSOS, 2011) e os Focos da Aprendizagem Docente (ARRUDA; PASSOS; FREGOLENTE, 2012).

Nesta investigação, propusemos a utilização desses dois instrumentos aplicados a entrevistas de três estudantes de um curso de licenciatura em Física, que relatam suas impressões sobre seus estágios supervisionados realizados em escolas da região central do estado do Paraná. 
O instrumento para análise da ação do professor em sala de aula é usado como uma lente analítica sobre os Focos de Aprendizagem Docente (FAD). A ideia de lente analítica é utilizada em analogia com o objeto óptico lente, frequentemente empregado como instrumento físico para ampliar, reduzir, focalizar e corrigir imagens em nosso cotidiano, possibilitando melhor visão e revelando aspectos e características dos sistemas observados. O instrumento para análise do professor em sala de aula nos trouxe outras possibilidades de interpretação do cenário em investigação, proporcionando o estudo do significado das evidências da aprendizagem docente apresentada pelos estudantes durante suas práticas profissionais.

Organizamos este artigo - em que trazemos os resultados dessa reflexão e aplicação - da seguinte forma: inicialmente, apresentamos o instrumento para a análise da ação do professor em sala de aula e sua fundamentação teórica; em seguida, trazemos os Focos da Aprendizagem Docente e sua fundamentação; na sequência, temos o contexto da pesquisa; os procedimentos metodológicos; a apresentação e a análise dos dados; e, por fim, as considerações finais para esse movimento investigativo.

\section{O instrumento para a análise da ação do professor em sala de aula: para além da gestão de conteúdo e gestão de classe}

\section{O sistema didático: gestão de conteúdo e gestão de classe}

Uma sala de aula pode ser representada pelo que vários autores denominaram por sistema didático ou triângulo didático ${ }^{5}$. Essa estrutura denominada sistema didático é constituída por três "lugares" e suas inter-relações, em que $P$ representa o professor, $E$ diz respeito aos estudantes e $S$ está relacionado ao saber, e suas inter-relações (CHEVALLARD, 2005).

Um conjunto de sistemas didáticos (ou seja, um conjunto de salas de aula) forma o sistema de ensino. A estrutura toda se encontra aberta ao meio externo, à sociedade, estando em constante interação com ela e dela sofrendo interferências em seu funcionamento. O processo de interação entre o sistema de ensino e a sociedade é mediado pela noosfera, verdadeira "peneira por onde se opera a interação entre esse sistema e o entorno social" (CHEVALLARD, 2005, p. 28). Na noosfera o funcionamento didático é pensado, discutido, produzido, teorizado, planificado e definido, a partir do debate de ideias, de problemas e de soluções (CHEVALLARD, 2005).

Em nossas últimas investigações, temos nos dedicado a entender as relações com o saber (CHARLOT, 2000) que se estabelecem em um sistema didático (ARRUDA; LIMA; PASSOS, 2011). Em especial, nos interessamos em aprofundar nossa compreensão do que tem sido designado de gestão de conteúdo e de gestão de classe. Em nossa visão, a gestão de conteúdo e a gestão de classe podem ser interpretadas como a gestão das relações do professor com o saber (conteúdo), com o ensino e com a aprendizagem dentro de um sistema didático. Tanto

\footnotetext{
${ }^{5} \mathrm{O}$ sistema didático, também chamado de triângulo didático ou triângulo pedagógico, possui sua origem em Platão (GAUTHIER; TARDIF, 2013), mas foi representado e estruturado de maneiras diferentes em abordagens distintas por vários autores (CHEVALLARD, 2005; HOUSSAYE, 1988; MEIRIEU, 1987).
} 
Gauthier et al. (2006) quanto Tardif (2002) consideram estas tarefas como sendo as duas principais funções que estruturam a ação do professor em sala de aula, também denominadas por eles de condicionantes.

A gestão de conteúdo pode ser definida como "o conjunto das operações organizadas para levar o aluno a aprender o conteúdo"; é a tarefa de "dar o programa, de assegurar-se de que os alunos dominam os diversos elementos do conteúdo, de incutir o gosto pelo estudo das diversas matérias etc.” (GAUTHIER et al., 2006, p. 138), abrangendo o planejamento do ensino de um modo geral, ou seja, o planejamento dos conteúdos, atividades, objetivos, estratégias, avaliações etc. (GAUTHIER et al., 2006). Enquanto a gestão de classe refere-se a um "conjunto de regras e de disposições necessárias para criar e manter um ambiente ordenado favorável tanto ao ensino quanto à aprendizagem" (GAUTHIER et al., 2006, p. 240), envolvendo a manutenção da ordem em sala de aula, o planejamento das regras, das medidas disciplinares, o estabelecimento de rotinas, desenvolvimento da responsabilidade etc., que visam tornar o ambiente propício à aprendizagem (GAUTHIER et al., 2006).

Tanto Tardif quanto Gauthier apontam que a gestão de conteúdo e a gestão de classe são “o próprio cerne da profissão" (TARDIF, 2002, p. 219). No entanto, como apontam Arruda, Lima e Passos (2011, p. 143), ao enfatizarem apenas o gerenciamento do conteúdo e da classe, tanto Tardif quanto Gauthier, parecem se esquecer de que o professor - enquanto uma pessoa, um sujeito - "tem de gerir também a sua própria aprendizagem, o seu próprio desenvolvimento". Por isso, afirmam que: "[...] a tarefa de gerir a si mesmo, sua aprendizagem, sua identidade, seus desejos, seu envolvimento, também deve ser incluída dentre as tarefas que estruturam a ação do professor em sala de aula" (ARRUDA; LIMA; PASSOS, 2011, p. 143. Grifo dos autores).

A partir desses pressupostos, Arruda, Lima e Passos (2011) buscam avançar na ideia dos condicionantes de Tardif e de Gauthier, repensando as tarefas do professor em sala de aula, de tal modo que a tarefa de gerir seu próprio desenvolvimento possa ser incluída. Uma solução, então, é apontada para essa questão a partir das ideias de Chevallard e de Charlot ${ }^{6}$.

Tomando por base o conceito de sistema didático, propõe-se que as tarefas do professor vão além dessas duas tarefas: trata-se mais de gerir relações epistêmicas, pessoais (identidade) e sociais com o saber (conforme definidas por Charlot), e relações com o conteúdo disciplinar, com o ensino e com a aprendizagem dos alunos. Tendo por princípio tais ideias, foi construído um instrumento denominado Matriz 3x3 (quadro 1), o qual pode ser utilizado para a análise da ação do professor em sala de aula.

Para apresentar de forma adequada esse instrumento e, também, sua fundamentação teórica, descrevemos, a seguir, os principais aspectos da teoria da relação com o saber de Charlot, associando-a, posteriormente, às ideias de Chevallard. Como resultado dessa descrição e sistematização, é construída a Matriz 3x3 com as novas tarefas para o professor em sala de aula.

\footnotetext{
${ }^{6}$ A teoria da relação com o saber ou a problemática da relação com o saber possui três vertentes. Charlot (2005) trata a questão da relação com o saber a partir de uma perspectiva sociológica; Chevallard (2005), a partir do funcionamento didático da relação formada entre professor, saber e aluno; e Beillerot, Blanchard-Laville e Mosconi (1996) abordaram a relação com o saber a partir da área da psicanálise.
} 


\section{A relação com o saber}

Para Charlot $(2000,2005)$, a questão do saber e a questão do aprender se interpenetram, em função de uma condição antropológica original: o ser humano nasce inscrito em um mundo (simbólico) no qual está submetido a uma necessidade, uma obrigação, a obrigação de aprender, pois o sujeito só pode tornar-se ser humano aprendendo, apropriando-se do mundo, relacionando-se com o mesmo. Para o autor, toda relação com o saber (e, também, com o aprender) é uma relação com o mundo, com o outro e consigo mesmo.

Essa relação também pode ser pensada como epistêmica, pessoal e social, conforme descrito em adaptação da versão original de Charlot (2000, p. 69 apud ARRUDA; LIMA; PASSOS, 2011, p. 145):

A. A relação epistêmica com o saber: diz respeito à relação com o saber enquanto um objeto do mundo a ser apropriado e compreendido; um saber dotado de objetividade, consistência e estrutura independentes; um saber "existente em si mesmo", "depositado em objetos, locais e pessoas" e imerso em um "universo de saberes distinto do mundo da ação, das percepções e das emoções" (CHARLOT, 2000, p. 69).

B. A relação pessoal com o saber: diz respeito à "relação de identidade com o saber"; o saber enquanto objeto que faz sentido, que é parte da história pessoal do sujeito, de sua vida e de suas expectativas (CHARLOT, 2000, p. 72); é o saber enquanto objeto de desejo, de interesse; o saber que o sujeito "gosta" e que o faz mobilizar-se à sua procura. C. A relação social com o saber: diz respeito ao fato que o sujeito nasce inscrito em um espaço social, ocupando uma posição social objetiva que lhe definem o contexto inicial em que ele vai se relacionar com o saber; nesse meio o saber possui valores dados pela comunidade em que o sujeito vive, recebendo o impacto das expectativas e aspirações de outros com relação a ele. (CHARLOT, 2000, p. 73)

Para o autor, aprender nesse mundo envolve um movimento interior que não pode existir sem o exterior de forma recíproca, ou seja, ensinar é uma ação que tem origem externa ao sujeito, mas só pode ter êxito se encontrar um movimento interno ao sujeito. Portanto, aprender é uma construção de si que só é possível pela intervenção do outro, também recíproca; ensinar é uma ação do outro que só tem êxito se encontrar o sujeito em construção (CHARLOT, 2001).

Assumindo a sala de aula como foco da investigação, é necessário esclarecer que por relação com o mundo entende-se a relação do sujeito com o mundo escolar, ou seja, um local com um fim específico, o campo onde estão presentes todos os atores que fazem parte deste mundo: os saberes da escola a serem ensinados; os alunos (os sujeitos que aprenderão tais saberes); os professores (que se dedicam ao ensino e à transmissão desses saberes); os profissionais envolvidos no ambiente educativo (administradores, diretores, supervisores, pedagogos etc.); e a parte física desse ambiente (o prédio, as salas de aula, laboratórios, auditórios, as carteiras etc.).

Esses são os principais aspectos do conceito e da definição da relação com o saber. A seguir, utilizando as relações epistêmica, pessoal e social com o saber e as ideias de Chevallard, 
apresentaremos como se configuram as novas tarefas a serem executadas pelo professor em sala de aula.

\section{As tarefas do professor em sala de aula}

A partir das considerações feitas, Arruda, Lima e Passos (2011, p. 147), tendo por referência as ideias de Chevallard e Charlot, afirmam que o sistema didático pode ser entendido como um sistema de relações com o saber em uma sala de aula padrão, em que E é o grupo de estudantes, $S$ é o saber a ser ensinado e $P$ representa o professor. Desta maneira, podem-se pensar as tarefas principais do professor $(\mathrm{P})$ na sala de aula (os condicionantes) como sendo de três tipos:

1. Gestão do segmento P-S: que diz respeito à gestão das relações do professor com o conteúdo.

3. Gestão do segmento P-E: que está relacionada à gestão das relações do professor com o ensino.

3. Gestão do segmento E-S: quando consideramos a gestão das relações do professor com a aprendizagem.

Essa abordagem para as tarefas (que também poderíamos pensar em funções, como indicado no início deste artigo) do professor em sala de aula traz avanços para a concepção da dupla tarefa do professor de Gauthier (2006) e Tardif (2002). Nas palavras de Arruda, Lima e Passos (2011, p. 147): “[...] não se trata de gerir objetos (o saber e a classe), mas sim de gerir relações (epistêmicas, pessoais e sociais); além disso, a tarefa do professor de gerir a si mesmo como profissional em desenvolvimento fica incluída nos condicionantes" (Grifo dos autores).

Tendo apresentado esses fundamentos e, considerando o sistema didático e das relações de saber de Charlot (2000), definidas como relações epistêmicas, pessoais (de identidade) e sociais com o saber, os autores Arruda, Lima e Passos (2011) constroem o Quadro 1, que foi denominado por Matriz 3x3 (quando consideramos as células internas - neste caso, as células denominadas por 'Setor').

Além disso, os autores afirmam que, para o Quadro 1, a questão da gestão do ensino e da aprendizagem em sala de aula se apresenta de maneira mais ampla, implicando que, agora, o professor tem de gerir suas relações com o conteúdo (segmento P-S), com o ensino que pratica (segmento P-E), e com a aprendizagem de seus alunos (segmento E-S), considerando que cada uma dessas gestões possui três dimensões: a epistêmica, a pessoal e a social.

Cada uma dessas células está especificada com mais detalhes no Quadro 2.

A Matriz 3x3 tem sido utilizada, sobretudo, na análise de entrevistas, mas já foi aplicada diretamente a gravações em sala de aula ${ }^{7}$.

\footnotetext{
${ }^{7}$ Ver Baccon (2011).
} 
Quadro 1. Matriz 3x3.

\begin{tabular}{|c|c|c|c|}
\hline $\begin{array}{l}\text { Novas tarefas do } \\
\text { professor }\end{array}$ & $\begin{array}{c}1 \\
\text { Gestão do segmento } \\
\text { P-S (conteúdo) }\end{array}$ & $\begin{array}{c}2 \\
\text { Gestão do segmento } \\
\text { P-E (ensino) }\end{array}$ & $\begin{array}{c}3 \\
\text { Gestão do segmento } \\
\text { E-S (aprendizagem) }\end{array}$ \\
\hline $\begin{array}{c}\mathbf{A} \\
\text { Epistêmica }\end{array}$ & $\begin{array}{l}\text { Setor } 1 \mathrm{~A} \\
\text { Diz respeito ao conteúdo } \\
\text { enquanto objeto a ser } \\
\text { compreendido pelo } \\
\text { professor. }\end{array}$ & $\begin{array}{l}\text { Setor } 2 \mathrm{~A} \\
\text { Diz respeito ao ensino } \\
\text { enquanto atividade a } \\
\text { ser compreendida pelo } \\
\text { professor. }\end{array}$ & $\begin{array}{l}\text { Setor } 3 \mathrm{~A} \\
\text { Diz respeito à } \\
\text { aprendizagem } \\
\text { enquanto atividade a } \\
\text { ser compreendida pelo } \\
\text { professor. }\end{array}$ \\
\hline $\begin{array}{c}\text { B } \\
\text { Pessoal }\end{array}$ & $\begin{array}{l}\text { Setor 1B } \\
\text { Diz respeito ao conteúdo } \\
\text { enquanto objeto pessoal. }\end{array}$ & $\begin{array}{l}\text { Setor } 2 \mathrm{~B} \\
\text { Diz respeito ao ensino } \\
\text { enquanto atividade } \\
\text { pessoal. }\end{array}$ & $\begin{array}{l}\text { Setor } 3 \mathrm{~B} \\
\text { Diz respeito à } \\
\text { aprendizagem enquanto } \\
\text { atividade pessoal. }\end{array}$ \\
\hline $\begin{array}{c}\text { C } \\
\text { Social }\end{array}$ & $\begin{array}{l}\text { Setor } 1 \mathrm{C} \\
\text { Diz respeito ao conteúdo } \\
\text { enquanto objeto social. }\end{array}$ & $\begin{array}{l}\text { Setor } 2 \mathrm{C} \\
\text { Diz respeito ao ensino } \\
\text { enquanto atividade } \\
\text { social. }\end{array}$ & $\begin{array}{l}\text { Setor } 3 \mathrm{C} \\
\text { Diz respeito à } \\
\text { aprendizagem enquanto } \\
\text { atividade social. }\end{array}$ \\
\hline
\end{tabular}

Fonte: Arruda, Lima e Passos (2011, p. 147).

\section{Focos da aprendizagem docente}

O segundo instrumento a ser utilizado em nossa análise foi denominado de Focos da Aprendizagem Docente, ou simplesmente FAD (ARRUDA; PASSOS; FREGOLENTE, 2012). Os FAD foram construídos em analogia com os focos da aprendizagem científica (strands of science learning) propostos no relatório denominado Learning science in informal environments: people, places, and pursuits (NATIONAL RESEARCH COUNCIL, 2009). Os autores partiram da seguinte questão: "Será que os focos da aprendizagem científica poderiam ser transpostos para o campo da formação de professores, servindo como instrumento para captar e avaliar a aprendizagem docente?” (ARRUDA; PASSOS; FREGOLENTE, 2012, p. 5).

A partir desse questionamento, esses pesquisadores foram construindo e justificando - passo a passo - cada um dos focos, de maneira que, ao final, foi possível estruturar os FAD, conforme o Quadro 3.

Cabe ressaltar que as ideias e os conceitos apresentados nos FAD são amplamente conhecidos e têm sido debatidos por pesquisadores da área de formação de professores há vários anos, bem como a vinculação entre os conceitos expostos foram passo a passo construídos e justificados no trabalho de Arruda, Passos e Fregolente (2012). Diante disso, consideramos desnecessário nos alongarmos - neste artigo - descrevendo, de forma particularizada, cada um dos FAD. 
Quadro 2. Descrição dos setores da Matriz 3x3.

Setor $1 A$. Diz respeito: à relação epistêmica do professor com o conteúdo; às maneiras como dele se apropria e a busca por compreendê-lo cada vez mais; à relação com os objetos e os locais onde o conteúdo pode ser encontrado, como livros, revistas, vídeos, internet, biblioteca, universidades etc.

Setor 1B. Diz respeito: à relação pessoal do professor com o conteúdo; ao sentido que o conteúdo adquire para ele e quanto determina sua identidade profissional; a quanto o professor gosta e se envolve com a matéria que ensina; a como ele avalia sua própria compreensão da mesma etc.

Setor 1C. Diz respeito: aos conteúdos escolares, enquanto objeto de trocas sociais em uma comunidade específica; a quanto o professor partilha de uma comunidade de educadores e dos eventos que esta realiza; à sua relação com as pessoas que detêm o conhecimento; às suas identificações e ideais; à sua busca por aperfeiçoamento por meio do convívio com outros professores, participação em cursos etc.

Setor $2 A$. Diz respeito: à relação epistêmica do professor com o ensino; à sua busca por compreendêlo melhor e às suas reflexões sobre a atividade docente e sobre a formação do professor; à sua percepção e reflexões sobre o seu próprio desenvolvimento como professor; às maneiras como realiza, avalia e procura melhorar o ensino que pratica; à sua relação com os materiais instrucionais, experimentos, instrumentos; às maneiras como realiza o planejamento dos objetivos, conteúdos, atividades, avaliação, recursos materiais etc.

Setor 2B. Diz respeito: à relação pessoal do professor com o ensino; a como se autoavalia como professor e como trabalha suas inseguranças; ao sentido pessoal que atribui ao ato de ensinar e quanto isso influi em sua identidade profissional; a quanto ele gosta de ensinar; ao seu estilo como professor e ao modo pessoal de se relacionar e aplicar as regras e normas de conduta; às responsabilidades, valores que se imputa enquanto educador etc.

Setor 2C. Diz respeito: ao ensino enquanto atividade social e interativa; às dificuldades e inseguranças pessoais produzidas em decorrência da interação com os outros (alunos, pais, professores, administradores etc.); às habilidades do professor para negociar com os alunos valores e comportamentos para que consiga ensinar e gerenciar o funcionamento da sala de aula; aos esforços que ele faz para conseguir apoio dos demais agentes sociais, cujas opiniões e avaliações afetam sua segurança, posição e sua autoridade enquanto professor etc.

Setor $3 A$. Diz respeito: à relação epistêmica do professor com a aprendizagem; à sua busca por compreender as maneiras como os alunos a realizam; à sua percepção e reflexão sobre as relações dos alunos com os conteúdos, às ideias prévias dos alunos e suas dificuldades de aprendizagem etc.

Setor 3B. Diz respeito: à relação pessoal do professor com a aprendizagem de seus alunos; ao sentido que esta adquire e quanto determina sua identidade profissional; às preocupações do professor com o envolvimento, motivação e interesse dos alunos e com a qualidade das interações na sala de aula; à sua capacidade pessoal de interferir e gerenciar a relação dos alunos com o conteúdo etc.

Setor $3 C$. Diz respeito: à aprendizagem enquanto atividade social e interativa; à manutenção de um ambiente propício às interações e à aprendizagem dos alunos; ao gerenciamento dos trabalhos e demais atividades em grupos etc.

Fonte: Arruda, Lima e Passos (2011, p. 148). 
Quadro 3. Focos da Aprendizagem Docente (FAD).

Foco 1 [nteresse pela docência]. O estudante experimenta interesse, envolvimento emocional, curiosidade, motivação, mobilizando-se para exercer e aprender, cada vez mais, sobre a docência.

Foco 2 [Conhecimento prático da docência]. A partir do conhecimento na ação e com base na reflexão na ação, o estudante desenvolve o conhecimento de casos, um repertório de experiências didáticas e pedagógicas que orientam a sua prática cotidiana in actu.

Foco 3 [Reflexão sobre a docência]. Frente a novos problemas originados de sua prática, os quais não conseguiu resolver no momento em que ocorriam, o futuro professor, com base em instrumentos teóricos, analisa a situação sistematicamente, envolvendo-se com a pesquisa e reflexão a posteriori sobre sua prática e o seu conhecimento acumulado sobre ela, de modo a resolver os problemas inicialmente detectados. Trata-se de desenvolver a dimensão da pesquisa no futuro professor.

Foco 4 [Comunidade docente]. O estudante participa de atividades desenvolvidas em uma comunidade docente, aprende as práticas e a linguagem da docência com outros professores ou futuros professores, assimilando valores dessa comunidade e desenvolvendo a reflexão coletiva.

Foco 5 [Identidade docente] ${ }^{8}$. O estudante pensa sobre si mesmo como aprendiz da docência e desenvolve uma identidade como alguém que se tornará futuramente um professor de profissão.

Fonte: Arruda, Passos e Fregolente (2012, p. 32-33).

\section{O contexto da pesquisa e os procedimentos metodológicos}

Nossa pesquisa foi desenvolvida no contexto da disciplina Estágio Supervisionado III (curso de licenciatura em Física - anos 2008 e 2009 - de uma Faculdade do centro do Estado do Paraná), com carga horária de duzentas horas, sendo 67 horas destinadas a atividades práticas e 133 horas cumpridas em atividades teóricas, tais como: planejamentos, elaboração de projetos, confecção de material didático, produção escrita do estágio e outras, conforme solicitação do professor supervisor do estágio.

\footnotetext{
${ }^{8} \mathrm{~A}$ identidade docente ou identidade do professor tem sido abordada de maneiras muito diferentes: como narrativas que os professores criam para explicar a si mesmos e a suas vidas no âmbito escolar; como metáforas que podem orientar ou resultar numa compreensão do papel do professor, a influência de uma ampla gama de fatores contextuais, sobre os professores e suas práticas; como o conjunto de conhecimentos, habilidades, competências e valores para o desenvolvimento de suas práticas. $\mathrm{O}$ tema identidade docente é complexo e mesmo um exame superficial da literatura revela que não há uma definição clara e há muito para se compreender sobre a identidade do professor e sua importância na formação docente (BEAUCHAMP; THOMAS, 2009). Mas podemos afirmar que algumas características são inerentes à identidade docente: a identidade do professor é um processo contínuo, é dinâmico e instável, ou seja, um fenômeno em evolução constante, podendo envolver a pessoa humana e seu contexto.
} 
Realizamos entrevistas semiestruturadas com os estudantes do curso, e as questões deflagradoras para a coleta foram: "O que foi a experiência do estágio para você? Você quer ser professor de Física?" Contudo, a partir do momento em que o estudante passava a dar seu depoimento, outras questões eram formuladas com a intenção de aprofundar a discussão e o detalhamento de seus comentários, suas percepções e preocupações a respeito do estágio supervisionado que estava realizando ou tinha realizado.

O processo de categorização seguiu os procedimentos usuais da análise textual discursiva, conforme discutida em Moraes (2003), que envolve: a fragmentação dos dados (entrevistas, por exemplo) em unidades de análise, seguida do reagrupamento das mesmas, segundo características comuns evidenciadas pelos significantes; e, posteriormente, agrupamento dos significantes segundo as categorias (neste caso, estabelecidas a priori), de modo que a tendência geral é construir um discurso coerente e dotado de alguma unidade a partir da seleção de falas (unidades de análise) que se acomodam e relacionam com o referencial adotado.

Os dados foram utilizados nos processos de interpretação e análise em três etapas: na primeira etapa, os trechos das falas de cada um dos estudantes foram categorizados a partir dos FAD (assumidos como categorias); em seguida, foi construída uma tabela em que é possível registrar cada um dos FAD, mostrando a distribuição nas falas em termos dos cinco focos da aprendizagem docente; na sequência, esses resultados são analisados e algumas considerações sistematizadas.

$\mathrm{Na}$ segunda etapa, o mesmo procedimento foi realizado com as entrevistas em sua totalidade, porém, agora, buscando enquadrar os trechos das falas de cada um dos estudantes nos setores da Matriz 3x3 (Quadro 1), e uma posterior análise também é realizada.

$\mathrm{Na}$ terceira etapa, procuramos utilizar a Matriz 3x3 considerando-a como uma lente analítica, que nos auxiliasse a visualizar, de forma pormenorizada, cada um dos focos categorizados a partir das falas dos estudantes, isto é, aplicamos a Matriz 3x3 nos fragmentos que já estavam agrupados em cada um dos focos. Por meio da descrição e do significado de cada um dos setores da Matriz, buscamos visualizar e compreender melhor o foco da aprendizagem docente em análise. Para essa etapa de organização e interpretação, duas questões nos mobilizaram: O que nos revela a Matriz 3x3, quando visualizamos cada um dos focos a partir da mesma? Quais características dessa aprendizagem docente são expostas ou tornam-se mais evidentes?

\section{Os dados, sua apresentação e análise}

Neste artigo trazemos (por questão de espaço e por opção no detalhamento da análise das informações) os dados, as discussões e as análises referentes a três entrevistas com os estudantes de uma licenciatura em Física do Estado do Paraná (estagiários), designados por E1, E2 e E3. Explicitamos na sequência, de forma resumida, alguns procedimentos que contribuíram com a organização do material a ser analisado (leitura flutuante das entrevistas) até chegarmos às considerações finais (inferências conclusivas) relativas a esse cenário em observação e estudo.

i) Trazemos a transcrição de parte de uma fala, para cada sujeito da pesquisa; as falas são formadas por frases, cada uma delas indicada por um número.

ii) Em seguida, organizamos essas unidades de busca e de pesquisa em tabelas (distintas para cada acadêmico entrevistado), e que trazem os comentários relativos a cada um dos 
focos de aprendizagem docente (tabelas 1, 3 e 5), organizados em suas colunas (segundo nossa interpretação).

iii) Esses fragmentos dos relatos são analisados e alguns comentários são sistematizados a respeito da caracterização do sujeito da pesquisa, a partir da distribuição de suas frases nessas células das tabelas 1,3 e 5 .

iv) $\mathrm{Na}$ continuidade, nos dedicamos a acomodar as entrevistas segundo as descrições que caracterizam cada uma das células da Matriz 3x3 (quadro 1), isto é, para cada um dos estudantes estagiários (sujeitos da pesquisa), seus depoimentos - já fragmentados e numerados - são acomodados em uma tabela semelhante ao Quadro 1, gerando três tabelas novas (tabelas 2, 4, 6), uma para cada acadêmico.

v) Essas acomodações (tabelas 2, 4, 6) são interpretadas considerando os fragmentos das entrevistas ali alocados, e uma análise seguida de comentários é estruturada.

vi) Por fim, retomamos a Matriz 3x3 de cada um dos estagiários E1, E2 e E3 (tabelas $2,4,6$ ), respectivamente, e voltamos a observar, interpretar e inferir sobre cada uma das tabelas que acomodavam as frases relativas aos FAD (tabelas 1, 3, 5) dos estagiários em análise, ou seja, "com os óculos da Matriz 3x3 de cada um deles" observamos, novamente, as tabelas 1, 3 e 5, evidenciando outros resultados, por vez, provenientes de uma análise mais aprofundada sobre as percepções de cada um dos entrevistados com relação ao processo de estágio supervisionado.

A seguir, trazemos parte desses registros interpretativos, contudo, indicamos que as argumentações conclusivas que apresentamos neste artigo consideram os dados coletados em sua completude.

\section{Estagiário E1}

Eu acho que é uma experiência válida que [1], é muito importante na formação de professores, além do que é a noção no caso do que é você conduzir uma aula [2]. A questão dos alunos não é uma simulação, por exemplo, como a gente faz aqui com os colegas [3]. Lá é real, pra você ter mesmo a noção, isso é importante pra todos [4]. O que eu aprendi durante o estágio, é que é diferente daqui, por exemplo, apresentar um seminário [5]. No estágio você se preocupa redobrado, você busca muito mais coisas, você procura estudar não só o que você vai apresentar ali [6], você tem que estudar as coisas que vêm antes, tudo aquilo que está por trás [7], para no caso de uma pergunta, por exemplo, não te colocarem na parede [8]. Quando eu comecei a estudar eu tinha muita dificuldade para falar assim [9], apresentar um trabalho era duro! [10] Agora já não, o estágio ajudou bastante pra que eu me soltasse [11]. Eu quero ser professor já ab! [12] Estudei pra isso e isso é uma coisa que en gostei no estágio ehb! [13].

Tabela 1. Acomodação e caracterização das falas de E1 segundo os FAD.

\begin{tabular}{cccccc}
\hline Estagiário 1 & Foco 1 & Foco 2 & Foco 3 & Foco 4 & Foco 5 \\
\hline Frases & $1,2,5,12$ & $3,4,6,7,8,9,10,11$ & & & $6,7,8,10,11,12,13$
\end{tabular}

Fonte: Elaborada pelos autores. 
O estagiário E1, de acordo com as análises das frases e a acomodação registrada na Tabela 1, demonstra maior preocupação com os Focos 2, 1 e 5 - nessa ordem, segundo a frequência com que foram relatados e acomodados.

Com relação ao Foco 1 - interesse pela docência -, E1 comenta sobre seu interesse chamando atenção para a importância dessa experiência do estágio para o desenvolvimento da sua prática profissional. Uma compreensão desta prática é manifestada no Foco 2, como certos conhecimentos adquiridos in actu, demonstrando que o estudante desenvolveu conhecimentos sobre a prática pedagógica. Isso é explicitado nas frases de (3) a (8).

No que diz respeito ao Foco 5 - relacionado à identidade docente -, esse estagiário apresenta um número de ocorrências significativas. Em seus relatos, é possível observar evidências do desenvolvimento de uma identidade docente e de como o estudante se refere a si como um aprendiz da profissão de professor, manifestando-se em relação à sua prática em sala de aula ou quando demonstra envolvimento com o ato de ser professor.

Em resumo, E1 se 'vê' como futuro professor ("en quero") e desenvolve sua identidade de acordo com sua futura profissão. Fica evidente, também, um conhecimento obtido por meio da ação, em sua prática cotidiana.

Essas manifestações indicam que E1, por meio da realização do estágio supervisionado, conseguiu identificar seu gosto pela docência, sua satisfação pessoal e certificar-se de certos conhecimentos adquiridos para o desenvolvimento da futura profissão, quando relata sobre a necessidade de estudar o que vai apresentar e os demais conteúdos vistos até o momento.

Tabela 2. Acomodação e caracterização das falas de E1 segundo a Matriz 3x3.

\begin{tabular}{lccc}
\hline $\begin{array}{c}\text { Estagiário } \\
\mathbf{E 1}\end{array}$ & $\begin{array}{c}\mathbf{1} \\
\text { Gestão do segmento P-S } \\
\text { (conteúdo) }\end{array}$ & $\begin{array}{c}\mathbf{2} \\
\text { Gestão do segmento P-E } \\
\text { (ensino) }\end{array}$ & $\begin{array}{c}\mathbf{3} \\
\text { Gestão do segmento E-S } \\
\text { (aprendizagem) }\end{array}$ \\
\hline $\begin{array}{l}\text { A Epistêmica } \\
\text { B Pessoal }\end{array}$ & 6,7 & $1,2,3,4,5$ \\
C Social & & $6,9,10,11,12,13$ & \\
\hline
\end{tabular}

Fonte: Elaborada pelos autores.

Ao nos deslocarmos na Tabela 2 coluna a coluna, podemos observar que as falas de E1 estão predominantemente relacionadas ao ensino (coluna 2), com poucas incidências relativas ao conteúdo (coluna 1) e nenhuma incidência na coluna 3, cuja relação é com a aprendizagem. Fica evidente também, nessa acomodação, que as principais questões para E1 pairam sobre a relação epistêmica com o ensino (coluna 2 - linha 1 ) e a relação social com o ensino (coluna 2 - linha 2), revelando certa ênfase no processo identificação com a profissão docente.

Quanto à relação epistêmica, as preocupações de E1 giram em torno de sua compreensão sobre o ensino, de como busca compreendê-lo, suas reflexões sobre o ato de ensinar e a formação docente. 
No que diz respeito à identidade (relação pessoal com o ensino), o que se evidencia, em E1, é o destaque que ele dá: à sua autoavaliação como professor, suas inseguranças e como trabalha com elas, o sentido pessoal que confere ao ato de ensinar e a influência deste sentido na construção de sua identidade como professor, constituindo seu gosto por ensinar.

A partir deste momento, com “os óculos da Matriz 3x3 de E1”, iniciamos uma leitura do que ficou evidenciado na Tabela 1 (referente às acomodações dos FAD para E1).

Iniciando pelo Foco 1 - interesse pela docência -, o que se observa é um interesse pela docência com ênfase na relação com o saber enquanto relação epistêmica com o ensino (setor 2A) e relação de identidade com o ensino (setor $2 \mathrm{~B}$ ), conduzindo-nos à consideração de que seu interesse pela profissão de professor está, sobretudo, relacionado com seu entendimento a respeito do ato de ensinar (pelo menos nesse período de vida pelo qual está passando).

Quanto ao Foco 2 - conhecimento prático da docência -, uma dinâmica interessante é observada ao retomarmos os depoimentos de E1 já alocados nessa tabela e observados via sua própria Matriz 3x3 (Tabela 2), ou seja, "olhando" o Foco 2 por meio da Tabela 2, vemos a indicação de que o conhecimento prático para E1 está vinculado à relação com o saber enquanto relação epistêmica com o conteúdo (1A), relação epistêmica com o ensino (2A), relação de identidade com o ensino (2B) e relação social com o ato de ensinar (2C). Esse mapeamento das reflexões e manifestações de E1 permite-nos concluir que, com relação ao conhecimento prático, esse graduando: compreendeu o conteúdo a ser ensinado; as maneiras de como se apropriar deste conteúdo; elaborou certo entendimento, percepções e reflexões sobre o ensino e a formação docente; desenvolveu-se como professor; construiu uma relação de identidade com o ensino; aprimorou seu estilo como professor; desenvolveu uma forma de trabalhar as dificuldades, as inseguranças e o processo de autoavaliação; atribuiu um sentido pessoal ao ensino, o que influenciou na construção de sua identidade docente; assumiu o ensino como atividade social e interativa; observou as dificuldades e as inseguranças em função da interação com os outros (alunos).

Ao observarmos a maior incidência de acomodação das falas na relação de identidade com o ensino (2B), podemos destacar que o conhecimento prático da docência, para E1, passa, sobretudo, pela identidade com o ato de ensinar. Isso nos leva a algo deveras interessante, à constituição da identidade docente in actu, nos permitindo considerar que o conhecimento na ação (o ato em si de refletir, de solucionar o problema, da criação de um repertório de situações pedagógicas) está intimamente conectado à construção de sua identidade como professor, sua identificação com o ato de ensinar. À medida que E1 vai construindo um conhecimento em sua prática cotidiana, in actu, vai se constituindo sua identidade com o ensino, com o ato de ensinar. Ou seja, vai se construindo sua identidade docente. Outro destaque interessante neste movimento de constituição da identidade é a aceitação de que o sentido inverso neste processo pode acontecer, isto é, à medida que se constitui sua identidade como professor, o conhecimento prático é remodelado, reestruturado, reorganizado.

Tomando para nova análise o que temos alocado no Foco 5 (Tabela 1 referente aos depoimentos de E1) e observando-a pelas "lentes" da Tabela 2, fica evidente que a identidade docente para E1 depende da relação com o saber enquanto relação pessoal, de identidade (2B), o que para nós pode ser considerado como algo natural. Todavia, foi observado que os indícios de identidade docente para o estudante em questão possuem relação com o ato de ensinar como atividade social e interativa (2C), e com uma relação epistêmica com o conteúdo (1A) 
a ser ensinado. Portanto, a identidade docente está relacionada com a interação com o meio e os atores presentes no ambiente escolar, como alunos, professores etc.; e também com sua relação com o conteúdo em si, sua compreensão e as reflexões a respeito de seu conhecimento da matéria e do ensino.

\section{Estagiário E2}

Bom, o estágio aproxima a gente mais da realidade, lá você está em campo né [14]. Aqui dentro da sala uma coisa né, você dá uma aula pro seus colegas [15], outra coisa é você enfrentar uma sala de aula com quarenta alunos [16]. Você vê que a coisa é mais próxima da realidade [17], a experiência dessa vivência é melhor, porque você sabe o que o professorpassa [18], daí você sabe como reagir no momento que, no momento adequado e que dar aula não é a coisa mais difícil do mundo [19]. Uma coisa que eu adquiri no estágio é de como lidar com os alunos na sala de aula [20]. A experiência melhor foi que dar aula é muito prazeroso mesmo [21]. A gente se sente gratificado em ensinar [22], é o que o estágio proporciona, você está lá na sala de aula com os alunos [23]. É que nem eu falei uma coisa é que nem aqui você dá aula pra quem já sabe [24], outra coisa é você dar uma aula pra quem não sabe quase nada [25]. Aí você passa de um mero acadêmico a ser mediador, transmissor de conbecimento [26], isso é o que gratifica o professor [27]. O estágio só ajudou eu ter mais certeza, pois en quero ser professor [28], um professor diferente do que eu tive [29], quero ser um professor dinâmico que leve as experiências pra sala [30], totalmente diferente do que eu tive [31]. Quero ensinar Física e não matemática elaborada e aplicada à natureza! [32].

Tabela 3. Acomodação e caracterização das falas de E2 segundo os FAD.

\begin{tabular}{cccccc}
\hline Estagiário 2 & Foco 1 & Foco 2 & Foco 3 & Foco 4 & Foco 5 \\
\hline Frases & $21,22,23,24,25,26,27$ & $15,16,17,18,19,20$ & & & $28,29,30,31,32$ \\
\hline
\end{tabular}

Fonte: Elaborada pelos autores.

Da mesma forma que para E1, os relatos do acadêmico E2 foram acomodados somente nos Focos 1, 2 e 5, o que mostra seu interesse pela docência, pelo conhecimento prático da docência e pela constituição da identidade docente.

Após essa distribuição e verticalizando nossos "olhares" nos depoimentos alocados na coluna do Foco 1, temos que o interesse de E2 pela docência ancora-se na motivação e no envolvimento emocional, e isso pode ser ratificado pelos trechos das falas (21), (22), (26) e (27).

Com relação ao Foco 2 - conhecimento prático -, E2 relata que o estágio supervisionado proporcionou a ele situações de aquisição desse conhecimento relacionado à ação em sala de aula, e possibilitou o desenvolvimento de um repertório de experiências didáticas e pedagógicas 
para a orientação de sua prática profissional diária, como: saber lidar com salas com grande número de alunos, reagir para o controle da ordem em sala de aula e os momentos adequados para desencadear esse controle.

Quanto ao Foco 5, podemos verificar que E2 fala sobre si como futuro professor e em um processo de desenvolvimento de uma identidade como professor. Isso fica explícito quando retomamos as frases (28), (29) e (30) em sua entrevista e nelas encontramos as evidências de que E2 se vê como futuro professor; mobiliza-se para desenvolver sua identidade docente; com o estágio conseguiu identificar sua satisfação pessoal e o prazer em exercer a docência; certificouse de certos conhecimentos adquiridos para o desenvolvimento da profissão, motivando-se a aprender cada vez mais sobre essa prática profissional.

Tabela 4. Acomodação e caracterização das falas de E2 segundo a Matriz 3x3.

\begin{tabular}{lccc}
\hline $\begin{array}{c}\text { Estagiário } \\
\text { E2 }\end{array}$ & $\begin{array}{c}\mathbf{1} \\
\text { Gestão do segmento P-S } \\
\text { (conteúdo) }\end{array}$ & $\begin{array}{c}\mathbf{2} \\
\text { Gestão do segmento P-E } \\
\text { (ensino) }\end{array}$ & $\begin{array}{c}\mathbf{3} \\
\text { Gestão do segmento E-S } \\
\text { (aprendizagem) }\end{array}$ \\
\hline A Epistêmica & & $14,15,16,17,18,19,24$, & \\
B Pessoal & & 25,32 \\
C Social & $19,21,22,23,26,27,28$, \\
\hline
\end{tabular}

Fonte: Elaborada pelos autores.

A acomodação dos relatos de E2 na Tabela 4 mostra a convergência para as questões relacionadas ao ensino (coluna 2), sem qualquer incidência nas colunas 1 e 3 relativas às relações com o conteúdo e a aprendizagem, respectivamente.

Fica explícita, também, uma distribuição equilibrada nas células $(2 \mathrm{~A})$ e (2B), e uma única frase em (2C) - relação social com o ensino. Essa distribuição nos leva a concluir que E2 se preocupa demasiadamente com o controle da sala (buscando um estado de ordem); o gerenciamento de atividades e o conhecimento de ações a serem executadas. A identificação com o ato de ensinar é fortemente manifestada em suas falas, e o gosto e o prazer pessoal pela docência mobiliza-o de maneira significativa no exercício da sua prática profissional.

Assim como realizado para E1, a partir deste momento, vamos fazer uso dos "óculos da Matriz 3x3 de E2" (Tabela 4), e retomar a Tabela 3 a fim de compreendermos um pouco mais sobre as manifestações desse estagiário diante das questões que levantamos sobre o estágio supervisionado que ele realizou.

Com relação ao primeiro foco - Foco 1 - interesse pela docência -, notamos que, para E2, esse interesse está localizado, quase que exclusivamente, na relação pessoal com o ensino (2B) e, também, na relação epistêmica com o ensino (2A). Fica evidente, nos relatos, seu gosto e prazer pelo ensino, assim como seu estilo de professor e o sentido pessoal que atribui a essa 
possibilidade de ser professor. Sua autoavaliação e sua forte relação identitária com a profissão são as marcas de destaque no depoimento de E2.

No que diz respeito ao Foco 2, quando visualizado por meio do conhecimento prático a partir da Tabela 4, notamos que, para E2, esse conhecimento prático da docência manifesta-se via relação epistêmica com o ensino (2A) e a relação social com o ensino (2C), concentrando-se no setor (2A) e com apenas um relato no setor (2C). Mediante esse viés interpretativo, podemos destacar que E2, via Foco 2, ressalta a importância da compreensão a respeito do ato de ensinar, de suas reflexões, de seus entendimentos a respeito da formação docente e da atividade profissional, bem como do seu próprio desenvolvimento como professor. E complementa, relatando a respeito do ensino como atividade social e interativa (2C), das necessidades que surgem em decorrência do gerenciamento das relações com o outro (aluno) em sala de aula e que fica cristalizado em sua fala "Uma coisa que eu adquiri no estágio é de como lidar com os alunos na sala de aula".

Para finalizar esta análise, tomamos agora o que foi acomodado no Foco 5 (identidade docente). Por meio do que nos traz a Tabela 4, podemos inferir que a identidade docente, para E2, vincula-se com a relação com o saber, enquanto relação de identidade com o ensino (2B), o que, para nós, pode ser considerado um resultado natural. Possui incidência, também, no setor (2A), relação epistêmica com o ensino, algo também natural em se tratando do foco relativo à identidade docente. Para E2, a identidade docente está relacionada com o ato de ensinar em si, ou seja, como compreende este ensino e o sentido pessoal que atribui ao ato de ensinar.

\section{Estagiário E3}

Eu achei assim muito legal [33], primeiro porque a gente, como a professora fala, é diferente de como a gente imagina [34], aqui na graduação a gente pensa que é uma coisa né, quando você chega na sala de aula a gente vê que é diferente né [35]. Eu assim fiquei bem insegura assim sabe?! [36] Quando eu vi o professor na observação dando aula, ele falava muito bem, explicava e eu achei assim que ia me dar mal, até mais, ai depois [37]. Conversei bastante com ele [38]. Numa turma os alunos dele eram conbecidos meus sabe, então me identifiquei bastante, era uma turma do terceiro ano [39]. E nossa, foi muito interessante foi uma experiência bem legal [40]. Eu acho assim que a gente aprende bastante coisa né com o estágio, não só o fato de você tá ali, mas é diferente né [41]. Ah! Eu achei bem interessante numa observação que eu fui [42], então tinha assim uns alunos bem bagunceiros sabe!? [43] Assim bem mal educados, quando eu estava lá eles não estavam tão mal educados, mas eu vi assim enquanto eu estava perto da porta que eles eram muito mal educados [44]. Eu entrei né e o professor estava na sala, ai eles já começaram sabe, falar umas coisas feias lá no final da sala [45]. O professor parou na frente do quadro, cruzou os braços e ficou olhando pra eles [46]. Pensei. O professor não vai falar nada? E os alunos naquela baderna [47], um provocando o outro e chutando as carteiras [48]. Ai eu vi que o professor ficou só olhando para eles [49]. Puxa vida, o professor não vai fazer nada! [50] Ficou olhando pra eles, dai a pouco eles foram se acalmando e foram se acalmando, se acalmando, sentaram tudo [51]. Começaram se bater um no outro [52]. Olha lá o professor, vamos prestar atenção [53]. Foi muito interessante porque eu tenho alunos assim que são bem rebeldes e eu não tenho paciência, ai eu 
falo alto com eles, eles falam alto comigo, então vira aquela bagunça [54]. Ai eu achei bem interessante [55]. E até testei nas minhas aulas para ver se dava certo e deu certo mesmo! [56] Fiquei quietinha lá na frente do quadro e os alunos foram se acomodando eu vi que não adianta bater de frente com eles [57]. Isso que eu achei que mais levei do estágio é isso [58]. Não adianta você querer ir pra sala de aula como louca, gritar, que eles fazem igual ou pior [59]. Bem no primeiro ano eu falei sobre as leis de Newton. É uma coisa que já estava assim bem acostumada [60]. No terceiro ano o professorpediu para eu falar alguma coisa sobre campo magnético, então tinha algumas coisas assim, que eu não dominava tanto, tive que ir atrás, porque ele pediu pra mim, não deu pronto as coisas, pediu para eu ir atrás sabe! [61] Dai tive que ir atrás, tinha umas coisas assim bem!! [62] Tinha uns experimentos lá que usava umas coisas assim de imã [63]. Aí pensei, meu Deus do céu, como que vou fazer isso? [64] Tive que estudar bastante pra poder ir sabe! [65] Ele deu dois exercícios que eu não conseguia fazer, dai tive que estudar bastante, mas ele me ajudou [66]. Foi, foi legal, um professor muito gente boa!! [67] Já conhecia ele, ele é bem querido, e foi assim, ele atendeu bem e tudo, ele tem aquele jeitão dele, mas ele me explicou bem [68]. Ele falou oh quero que você, que você faça isso, isso e isso que é o que já estou trabalhando, esses exercícios eles já fizeram alguns, já sabem fazer, se tiver alguma dúvida! Eles já estão adiantados [69]. Então foi muito bom [70]. Me lembro, acho que uma das únicas que falou que não queria ser professora era eu [71]. Agora eu posso te dizer que en estou realizada [72]. Eu gosto assim de estar na sala explicando [73]. Os alunos encontram você na rua "Oi professora!!" é muito legal, nossa [74]. Você tem que correr atrás, tem que ver: Como que vou explicar isso? Que exercício que vou dar? Como que faço uma prova? Mas é legal isso! [75] Os meus colegas de trabalbo, sabe, eles, não todos, mas eles apoiam a gente que está começando agora, então é bem interessante, peço uma ajuda quando preciso [76]. Foi o primeiro estágio que eu fi: Que en comecei a ver que era legal [77]. Aí eu fui trabalhando né, comecei a gostar! [78] Eu só gostei este ano mesmo porque estou dando aula de Física, porque o ano passado eu estava dando aula de matemática e eu pego um pavor de dar aula de matemática [79]. Física!! Que não é aquelas contas. É laboratório, é experimento, é dia a dia, é cotidiano né. Dá pra relacionar tudo né! [80] E dai eu tenho uma turma lá do interior. Quando eu vou explicar para eles, eles já perguntam professora, o que isso tem a ver com o nosso dia a dia?'[81] Daí, já penso em alguma coisa pra falar pra eles [82]. Senão pra eles não há nada interessante [83]. Pessoal, onde eu trabalho até eles vão fazer um trabalho para feira com ciência. Uns vão fazer um chafariz. Outros vão fazer a latinha mágica [84]. Então me identifiquei agora que estou dando aula de Física [85]. Então estou achando muito interessante, até estes dias estava falando para minha mãe: "Nossa, valeu a pena estes três anos e meio, agora eu tenho certeza, antes não achava, que valeu a pena, antes realmente eu não queria" [86]. 
Tabela 5. Acomodação e caracterização das falas de E3 segundo os FAD.

\begin{tabular}{cccccc}
\hline Estagiário 3 & Foco 1 & Foco 2 & Foco $\mathbf{3}$ & Foco 4 & Foco $\mathbf{5}$ \\
\hline Frases & $33,40,41,70$, & $42,43,44,45,46,47,48$, & $61,62,63$, & 67,68, & $71,72,73$, \\
& $71,72,74,77$, & $49,50,51,52,53,54,55$, & $64,65,66$ & 69,76 & $74,75,81$, \\
& $78,79,85,86$ & $56,57,58,59,80,81,82$ & & & $82,85,84,86$ \\
\hline
\end{tabular}

Fonte: Elaborada pelos autores.

E3 foi o único, dentre os analisados para a apresentação dos resultados neste artigo, que apresentou relatos que puderam ser acomodados nos cinco focos de aprendizagem docente. Com maior incidência de frases alocadas nos Focos 2, 1 e 5, respectivamente, considerando as quantidades. Pode-se observar, também, que somente E3 se manifestou com relação ao que é possível ser caracterizado como Focos 3 e 4, reflexão sobre a docência e comunidade docente.

Quanto ao que se percebe sobre o Foco 1, o estagiário demonstra um envolvimento emocional, acompanhado de curiosidade e de mobilização para exercer e aprender a profissão docente.

Com respeito ao Foco 2, o conhecimento sobre o qual E3 relata se refere a situações de controle da sala e de como agir de maneira adequada e no momento apropriado, com o objetivo de manter a ordem nesse espaço - a sala de aula.

Com relação à reflexão sobre a docência (Foco 3), suas manifestações vão na direção do desenvolvimento de atividades para sua prática educativa, destacando a necessidade de estudar, de refletir e de buscar por uma melhor forma de implementar as atividades junto aos alunos na sala de aula.

A interação com os colegas de trabalho (Foco 4) - participação em uma comunidade docente - é um dos fatos que podemos destacar nos depoimentos de E3, sobretudo, quando relato a respeito do acolhimento que recebeu por parte do professor regente da sala em que estagiou e de seus outros colegas da escola.

A identidade docente (Foco 5) é evidenciada pelo estagiário, quando ele relata que já pensa em si como um futuro professor, desenvolvendo, assim, uma identidade profissional. Os trechos das frases de (72) a (75) e (81) a (83) nos mostram esses depoimentos.

Em resumo, a partir destas experiências, E3 demonstra: grande interesse pela profissão, motivação para atuar e se manter nesse processo, uma identidade docente em constituição e o destaque no relacionamento com outros professores, participando, efetivamente, de atividades propostas por membros dessa comunidade, que o levam a aprender a linguagem mais apropriada, as práticas mais adequadas e acumular um repertório de experiências, que o auxiliam na resolução de novos problemas originados na própria prática.

Ao nos depararmos com as acomodações dos fragmentos da entrevista na Tabela 6 , fica evidente a presença desses fragmentos em todos os setores da Matriz 3x3, fato que não se deu com os estagiários analisados anteriormente. É possível observar, ainda, a predominância desses relatos na coluna 2 (relativa ao ensino), sendo que os setores (2B) e (2C) são os que possuem maior frequência de representação. 
Aprofundando a compreensão da aprendizagem docente

Tabela 6. Acomodação e caracterização das falas de E3 segundo a Matriz 3x3.

\begin{tabular}{lccc}
\hline $\begin{array}{c}\text { Estagiário } \\
\text { E3 }\end{array}$ & $\begin{array}{c}\mathbf{1} \\
\text { Gestão do segmento P-S } \\
\text { (conteúdo) }\end{array}$ & $\begin{array}{c}\mathbf{2} \\
\text { Gestão do segmento P-E } \\
\text { (ensino) }\end{array}$ & $\begin{array}{c}\mathbf{3} \\
\text { Gestão do segmento E-S } \\
\text { (aprendizagem) }\end{array}$ \\
\hline A Epistêmica & $61,62,63,64,65,66,80$ & 75 & 81,82 \\
B Pessoal & $60,61,79,85$ & $33,34,35,36,40,41,42$, & 39,83 \\
& & $71,72,73,74,77,78,86$ & 84 \\
C Social & $67,68,69,70$ & $37,38,46,47,48,49,50$, & \\
& & $51,52,53,54,55,56,57$, & \\
& & $58,59,76$ & \\
\hline
\end{tabular}

Fonte: Elaborada pelos autores.

Nesse mesmo mapeamento do que foi acomodado, podemos observar algumas falas distribuídas ao longo da coluna 1 (referente ao conteúdo) e poucas ao longo da coluna 3 (aquela em que a aprendizagem torna-se o centro das preocupações).

Diversas interpretações podem ser realizadas a partir do que temos na Tabela 6, deslocando-nos coluna a coluna ou linha a linha ou de célula em célula, considerando aquelas em que temos maior frequência de relatos. A seguir, trazemos algumas conclusões sobre essas células com maior número de frases alocadas ou aquelas em que a interpretação dos depoimentos traz possibilidades de inferência e a frequência não precisa ser considerada, ou seja, são fatos que mencionamos uma única vez e que já dão pistas de nossas percepções. Vejamos alguns desses casos:

- As questões principais levantadas por E3 estão relacionadas à relação social com o ensino (2C), relação pessoal com o ensino (2B) e relação epistêmica com o conteúdo (1A), respectivamente. A incidência de relatos nas demais células é menor.

- Há outros pontos também apontados por E3 em seu depoimento, todavia, apresentam poucas incidências e estão relacionados: à relação pessoal com o conteúdo (1B), à relação social com o conteúdo $(1 \mathrm{C})$, à relação epistêmica com o ensino $(2 \mathrm{~A})$, à relação epistêmica com a aprendizagem (3A), à relação de identidade com a aprendizagem (3B) e à relação social com a aprendizagem (3C), preenchendo, assim, todos os setores da Tabela 6.

- Para E3, a relação com o saber, enquanto relação social com o ensino (2C), está diretamente relacionada com as dificuldades e as inseguranças a respeito do gerenciamento e da ordem, que precisa ser estabelecida na sala de aula. A interação com os alunos, de modo a conseguir ensinar e desenvolver a atividade educativa, é a principal preocupação manifestada pelo estagiário, quando nos debruçamos sobre esse aspecto da prática docente.

- Quanto à relação com o saber, enquanto relação pessoal com o ensino (2B), E3 apresenta, em seu depoimento, características voltadas para uma visão pessoal do ato de ensinar, que perpassa pelo seu estilo como professor, pelo seu gosto e prazer em dar aula e pela identificação com o processo de ensinar. Destacam-se, também, na análise dos relatos inseridos nessa célula, sua autoavaliação e a superação das inseguranças inerentes nesse momento es- 
pecífico de regência e de atuação na sala de aula, e a influência que essa prática teve sobre seu desenvolvimento profissional.

- A respeito da relação epistêmica com o conteúdo (1A), no depoimento de E3 percebemos que os pontos principais estão relacionados à compreensão dos conteúdos a serem ministrados; o desenvolvimento de atividades a serem trabalhadas com os alunos, assim como os experimentos a serem desenvolvidos.

- Ainda com relação à coluna 1 , as relações pessoal e social com o conteúdo (1B e 1C) trazem: aspectos do sentido que ele atribui àquele conteúdo, o envolvimento que possui com a matéria e as motivações que o levam a compreendê-lo melhor, bem como as relações e interações com os outros professores na busca por seu aperfeiçoamento.

- As reflexões, as percepções e as compreensões relacionadas ao ensino (assim como para os demais entrevistados) também foram assinaladas por E3, e sua acomodação pode ser vista em (2A) na relação epistêmica com o ensino.

- Ao observarmos as células (3A), (3B) e (3C) - que organizam a coluna 3 - relativas à aprendizagem, nota-se que os depoimentos do estagiário abordam: questões vinculadas às reflexões e às percepções sobre as relações que os alunos possuem com os conteúdos e os processos de aprendizagem, suas preocupações com o envolvimento desses alunos nesse processo, assim como a motivação e o interesse deles e, por conseguinte, sua preocupação em proporcionar um ambiente favorável às interações e à aprendizagem desses educandos relacionada à seleção de atividades que o auxiliem a atingir determinados objetivos.

Dando continuidade ao estudo das manifestações de E3, utilizaremos a Tabela 6 como uma lente analítica para melhor compreensão daquilo que foi alocado nos cinco focos relacionados ao processo de aprendizagem docente (Tabela 5).

Observando o que temos no Foco 1, percebemos, em E3, que o interesse pela docência se pauta na relação pessoal com o conteúdo (1B) e na relação pessoal com o ensino (2B), revelando uma identificação com o saber em questão, a Física, e com o ato de ensinar, isto é, o gosto, o envolvimento e o sentido pessoal que atribui ao conteúdo e ao ensino em si, e o que caracteriza seu interesse pela docência.

Quanto ao conhecimento prático da docência (Foco 2), E3 se manifesta por meio de uma rica combinação de fatores relacionados ao conteúdo, ao ensino e à aprendizagem, indicando que esse conhecimento adquirido está em conexão: com a relação epistêmica com o conteúdo (1A), com a relação de identidade com o ensino (2B), com a relação social com o ensino (2C) e com a relação epistêmica com a aprendizagem (3A). Portanto, questões como o entendimento a respeito do conteúdo e as maneiras com que dele se apropria; o sentido pessoal atribuído ao ensino; o gosto e a identificação com o ato de ensinar; as interações com os alunos na sala de aula; as ações para o gerenciamento de comportamentos e valores que visam ao bom funcionamento da dinâmica da sala de aula; a reflexão e a percepção a respeito da relação dos alunos com os conteúdos; os processos de aprendizagem dos alunos, estão presentes em seu depoimento.

Ao analisarmos o que está relacionado com o Foco 3 (reflexão sobre a docência), evidenciamos um movimento de interação com a relação com o saber, enquanto relação pessoal com o conteúdo (1B) e relação epistêmica com o conteúdo (1A). O sentido pessoal e o gosto pelo conteúdo, assim como sua busca por compreendê-lo são as características destacadas por ele no que diz respeito à reflexão sobre a docência. Fato que nos leva a considerar que a reflexão sobre a docência não é tanto uma reflexão sobre o ensino, mas, sim, uma reflexão e identificação a respeito do conteúdo. 
Os indícios sobre comunidade docente - Foco 4 - declarados por E3, estão interligados via relação social com o conteúdo (1C) e a relação social com o ensino (2C), um movimento esperado, e que possui características como: a partilha com a comunidade específica, ou seja, as relações e as interações com os outros professores na busca por seu aperfeiçoamento e pelo gerenciamento dos comportamentos e dos valores que visam ao bom andamento das atividades educativas em sala de aula.

O Foco 5 (relativo à identidade docente) aponta para aspectos que convergem para a relação de identidade: com o conteúdo (1B), com o ensino (2B) e com a aprendizagem (3B). E ainda apresenta indícios da relação epistêmica com o ensino (2A), com a aprendizagem (3A) e relação social com a aprendizagem (3C). Fatores como o gosto, o sentido pessoal, o envolvimento e a motivação com relação ao conteúdo, ao ato de ensinar e à aprendizagem dos alunos são os pontos principais evidenciados na fala de E3, bem como sua percepção, reflexão e compreensão acerca dos processos de aprendizagem e a aprendizagem como atividade social e interativa.

\section{Considerações finais}

De maneira geral, buscamos, nesta investigação, utilizar a Matriz 3x3 como uma lente analítica sobre os FAD evidenciados a partir da fala de três estudantes de licenciatura em Física. Essa utilização nos permitiu visualizar e caracterizar o significado de cada um dos focos para cada um dos estudantes estagiários, definindo, assim, movimentos específicos para cada estudante em relação aos FAD.

Semelhanças e diferenças interessantes podem ser observadas na caracterização de cada um dos focos por meio dos setores da Matriz, possibilitando compreender algumas relações entre os Focos e as relações epistêmica, pessoal e social com o conteúdo, com o ensino e com a aprendizagem, durante a realização do estágio de prática profissional destes futuros professores, e que foram manifestadas em seus depoimentos, trazendo à tona características específicas nos indícios de aprendizagem docente.

Assumindo a utilização da Matriz como uma lente analítica sobre os FAD, cremos que conseguimos identificar aspectos da formação docente na constituição do 'ser professor', específicos de cada estudante ou para um grupo de estudantes, fato que pode contribuir com outros estudos do processo de aprendizagem da docência.

Gostaríamos de enfatizar, também, que os dois instrumentos de análise - Matriz 3x3 e FAD - tiveram origens diferentes. A Matriz surgiu como consequência das reflexões sobre a formação de professores e a relação com o saber no contexto da educação formal, enquanto os FAD foram desdobramentos das pesquisas no campo da aprendizagem informal, elaborados em analogia com os Focos da Aprendizagem Científica ou FAC (ARRUDA et al., 2013). Ou seja, os FAD foram incursões no campo da formação de professores a partir de um instrumento criado para analisar a aprendizagem na educação informal.

Após a criação dos FAD, percebemos a possibilidade de articular as duas linhas de pesquisa. Este artigo apresenta uma dessas possibilidades em que a Matriz é aplicada como uma lente sobre as categorizações realizadas com os FAD, o que permite perceber modulações e nuances nas frases localizadas em cada um dos seus focos.

No momento, estamos trabalhando no sentido inverso, ou seja, na elaboração de uma Matriz mais geral, que possa ser aplicada a outras configurações de ensino e aprendizagem que 
ocorrem fora da escola. Trata-se, portanto, de buscar incursões no campo da educação informal, a partir de um instrumento criado para analisar a ação dos professores. Isso permitiria uma segunda articulação, dessa vez utilizando a nova Matriz como uma lente para analisar a aprendizagem, conforme categorizada a partir dos Focos da Aprendizagem Científica.

\section{Agradecimentos}

João Paulo Camargo de Lima agradece o apoio da Capes por meio de bolsa de pósdoutorado. Marinez M. Passos agradece o apoio da Fundação Araucária e Sergio de Mello Arruda agradece o apoio do CNPq.

\section{Referências}

ARRUDA, S. M.; BACCON, A. L. P. O professor como um lugar: uma metáfora para compreensão da atividade docente. Ensaio: pesquisa em educação em ciências, Belo Horizonte, v. 9, p. 1-20, 2007.

ARRUDA, S. M.; LIMA, J. P. C.; PASSOS, M. M. Um novo instrumento para análise da ação do professor em sala de aula. Revista Brasileira de Pesquisa em Educação em Ciências, São Paulo, v. 11, n. 2, p. 139-160, 2011.

ARRUDA, S. M.; PASSOS, M. M.; FREGOLENTE, A. Focos da aprendizagem docente. Alexandria, Florianópolis, v. 5, n. 3, p. 25-48, 2012.

ARRUDA, S. M. et al. O aprendizado científico no cotidiano. Ciência \& Educação, Bauru, v. 19, n. 2, p. 481-498, 2013.

BACCON, A. L. P. Um ensino para chamar de seu: um estudo sobre a gestão da matéria e a gestão de classe de professores de física do ensino médio. 2011. Tese (Doutorado em Ensino de Ciências e Educação Matemática) - Universidade Estadual de Londrina, Londrina, 2011.

BEAUCHAMP, C.; THOMAS, L. Understanding teacher identity: an overview of issues in the literature and implications for teacher education. Cambridge Journal of Education, Abingdon, v. 39, n. 2, p. 175-189. 2009.

BEILLEROT, J.; BLANCHARD-LAVILLE, C.; MOSCONI, N. (Org.). Pour une clinique du rapport au savoir. Paris: Hartmann, 1996.

CHARLOT, B. Da relação com o saber: elementos para uma teoria. Porto Alegre: Artmed, 2000.

Os jovens e o saber: perspectivas mundiais. Porto Alegre: Artmed, 2001.

Relação com o saber, formação de professores e globalização: questões para a educação hoje. Porto Alegre: Artmed, 2005. 
CHEVALLARD, Y. La transposicion didactica. Buenos Aires: Aique, 2005.

FLORES, M. A. The early years of teaching: issues of learning, development and change. Porto: Rés, 2004.

. A formação de professores e a construção da identidade profissional. In: SIMÃO, A. M. V.; FRISON, L. M.; ABRAHÃO, M. H. (Ed.). Autorregulação da aprendizagem e narrativas autobiográficas: epistemologia e práticas. Natal: EDUFRN, 2012. p. 93-113.

GAUTHIER, C.; TARDIF, M. A pedagogia: teorias e práticas da Antiguidade aos nossos dias. Petrópolis; Vozes, 2013.

GAUTHIER, C. et al. Por uma teoria da pedagogia: pesquisas contemporâneas sobre o saber docente. Ijuí: Ed. Unijuí, 2006.

GEE, J. P. Identity as an analytic lens for research in education. Review of Research in Education, Thousand Oaks, v. 25, n. 1, p. 99-125, 2000.

HARGREAVES, A. Foreword. In: TICKLE, L. The induction of new teachers. London: Cassell, 1994. p. vii-ix.

HOUSSAYE, J. Le triangle pédagogique. Berne: Peter Lang, 1988.

LUEHMANN, A. L. Identity development as a lens to science teacher preparation. Science Education, Hoboken, v. 91, n. 5, p. 822-839, 2007.

MEIRIEU, P. Apprendre, oui ... mais comment. Paris: ESF, 1987.

MORAES, R. Uma tempestade de luz: a compreensão possibilitada pela análise textual discursiva. Ciência \& Educação, Bauru, v. 9, n. 2, p. 191-211, 2003.

NATIONAL RESEARCH COUNCIL. Learning science in informal environments: people, places, and pursuits. Washington: The National Academies Press, 2009. Disponível em: <http://www.nap.edu/catalog/12190.html> Acesso em: 5 mar. 2014.

PETRIE, H. G.; OSHLAG, R. S. Metaphor and learning. In: ORTONY, A. (Org.). Metaphor and tought. Cambridge: Cambridge University Press, 1993. p. 579-609.

PIMENTA, S. G.; LIMA, M. S. L. Estágio e docência. São Paulo: Cortez, 2004.

TARDIF, M. Saberes docentes e formação profissional. Petrópolis: Vozes, 2002.

THOMAS, L.; BEAUCHAMP, C. Understanding new teacher' professional identities through metaphor. Teaching and Teacher Education, Oxford, UK, v. 27, n. 4, p. 762-769, 2011. 